\title{
Occurrence of Polymelia in 9-Week-Old Male Broi- ler: Anatomical and Radiological Aspects
}

\author{
Itopa E. Ajayi ${ }^{* 1}$ and Samuel Mailafia ${ }^{2}$ \\ ${ }^{1}$ Department of Veterinary Anatomy, University of Abuja, Nigeria. \\ ${ }^{2}$ Veterinary Teaching Hospital, University of Abuja, Nigeria
}

Received February, accepted for publication April 2011

\section{Abstract}

Polymelia was described in a 9week-old broiler chicken macroscopically and radiographically. The external features showed two normal limbs and one undeveloped extra-limb. This extra-limb was attached to the caudal region of the pelvic bone and was surrounded by a mass of muscular tissue. The extra-limb was formed at a joint with the pelvis, presenting a characteristic incompletely duplicated femur and tibia. Radiographical examination showed that the right half of the pelvis had an extra femur which was attached to the acetabulum in addition to the normal femur. Two other femurs were observed to have articulated with the pelvis at a point caudal to the right acetabulum. This phenomenon is very rare in chickens. Our findings, therefore, document the first report on the occurrence of polymelia in broilers in the Federal Capital Territory of Nigeria.

\section{Keywords}

Polymelia, Poultry, Radiography, Anatomy, Occurrence

\section{Introduction}

Congenital malformations of the limbs are among the most frequent congenital anomalies found in animals and humans (Alam et al., 2007). They may be multiple or may affect single parts of organ systems. Congenital anomalies of the skeletal system are common in domestic animals and birds (Arunprasad et al., 2009). However, the precise mechanism that regulates their development is not yet clearly understood (Bahador et al., 2007). These anomalies are usually associated with genetic factors including transgenes, chromosomes, and environmental agents including infectious agents, toxins, techniques involved in fertilization and certain management factors or a combina- 
tion of factors (Keeler et al., 1981; Rousseaux and Ribble, 1988; Newman et al., 1999). Such anomalies have also been associated with excessive division as seen in related problems such as polydactyla (supernumerary fingers or toes), polythelia (Supernumerary nipple) and polydontia (having more than the normal number of teeth) (Rahman et al., 2006).

Polymelia is a congenital anomaly which is defined as the presence of accessory $\operatorname{limb}(\mathrm{s})$ attached to the various body regions and could be classified as cephalomelia (extra limb attached to the head), notome lia (extra limb attached to the back bone), thoracomelia (extra limb attached to the thorax) and pygomelia (extra limb attached to the pelvis) based on the region affected (Leipold et al., 1983; Arunprasad et al., 2009; Hiraga et al., 1989; Fourie, 1990). Polymelia has been reported in human, mouse, chicken, calf and lamb around the world (Anderson et al., 1985; Herec et al., 1986; Harinarayana, 1992; Bahador et al., 2007). To the best of our knowledge, this is the first report of a notable case of polymelia in chickens in Gwagwalada, FCT.

As at present, there is no definitive etiologic knowledge of its origin. The understanding as to whether it is caused by genetic or environmental factors, or both, is not clearly known but it is confirmed that the susceptibility to an injurious environmental factors or to certain genetic agents varies with the various stages of bone development between species (Rahman et al., 2006). This could be a notable cause of this condition in chickens.

The aim of this article is to deduce the anatomic and radiologic facts of this case of polymelia in a fully grown broiler and to outline possible causes of the defect in birds with a view of preventing future occurrences.

\section{Case Description}

A nine week old broiler chicken was delivered to the Ambulatory unit of the Veterinary Teaching Hospital, University of Abuja, Nigeria, with the chief complaint of the presence of an extra limb in the caudal pelvic region. History revealed that the bird was raised with thirty others in a locally constructed wooden cage system and fed on broilers mash preparation. The bird grew and reached slaughter weight without any other problems. The aberration was presented with a request for its amputation.

Clinical examination revealed that the extra limb was attached to the 
caudo-dorsal region of the pelvis on the right side of the hip (Fig. 2). Its cranio-caudal axis of development was rotated in an angle of about 30 degrees in relation to the normal limb. The proximal part of the limb faced medial. The distal part of the limb ended with two digits as seen in Figure (3). Normal mass of muscles and connective tissues were palpated at the limb area especially in its proximal aspect. No movement and pain response was observed during clinical examination. The animal was in an apparently good state and no other anomaly was observed physically. Yet it was not able to use the extra limb accordingly.

Radiographic examination was used to determine the degree of malformation in the limbs as well as the type of articulation in both long bones and digits. A radiograph was taken in a ventrodorsal position with exposure factors $(50 \mathrm{Kv}, 300 \mathrm{~mA}$, and 15 seconds). This was done with the use of a fixed x-ray machine (SIEMENS, 8375040 G2107, Made in Germany). Radiographic and processing protocol was conducted according to the method documented by Hassan and Hassan (2003).

The radiographs revealed the presence of four femural bones. The first femural bone was normal with a normal tibia attached to it. The second femur had the same pelvic articulation as the first. The third and fourth femural bones had a common point of articulation caudal to the right acetabulum. However, the fourth limb appeared to be the most developed of the extra limbs (Fig. 4). It articulated with a rudimentary tibia distally and protruded externally. This externally visible limb ended up with two digits as seen in Fig (3).

Upon gross dissection of the normal limb, muscles groups of the hip and thigh including the coxocrural extensors, femorocrural extensors, coxofemoral extensors, coxocrural flexors, coxofemoral flexors and femorocrural flexors appeared normal. The extra limb 'D' (Fig. 4) was exactly similar but not well developed.

\section{Discussion}

Limbs develop at definitive positions. Limb formation begins with the activation of a group of mesenchymal cells in the somatic lateral mesoderm. The Apical ectodermal ridge produces fibroblast growth factor, which interacts with the underlying mesoderm to promote outgrowth of the limb by stimulating mitosis (Sinowatz, 2010). As much as the specific etiology of this teratologic defect is not precisely 
known, we suspect that some teratogens may be capable of stimulating mitosis at multiple sites.

Similar limb malformations have been linked to certain environmental and some genetic factors, teratogenic agents and drugs or to their combinations (Albarella et al., 2009). The occurrences of such defects in domestic birds such as broilers suggest that there are some widespread environmental factors that may be contributing to this problem. The increased concern and attention to these abnormalities by Veterinarians and field Biologists might assist in identifying their etiology. However, some common and seemingly overlooked environmental pollutants such as Polychlorinated Biphenyl Compounds (PCB) and mercury have also been incriminated in the cause of this congenital problem (Hays and Risebrough, 1972). PCBs for instance, are a class of organic compounds that are used as components of paints, cement, pesticides, cutting oils, hydraulic fluids, PCBcontaining wooden floor finish and carbonless copy paper (Rudel et al., 2008). This class of organic compounds could generally acts by inhibiting estradiol, an effect capable of leading serious developmental problems including skeletal developmental issues (Rudel et al., 2008). How- ever, to establish a relationship between defect and concentration of chemicals/extent of exposure, a large number of birds will have to be researched.

The exact cause of the deformity observed in our case study was not clear. In addition to the suspicion of environmental influence, genetic factors could also be considered. These could be from either defective genetics or from genetic agents that were associated with the foetal environment or from their interaction. It may have been transmitted vertically. This is because malformations represent an error that may have occurred early in development (Meteyer, 2000; Alam et al., 2007). However, in making this consideration, knowledge of normal developmental principles is necessary to design thoughtful investigations that will define the events involved in abnormal development in birds. This is because susceptibility to genetic agents varies with the stage of development and between species, and this susceptibility decreases with the advancement of foetal age (Alam et al., 2007; Rahman et al., 2006). In birds, development begins at the time an egg is fertilized and progresses by chemical communication between cells and cell layers. This communication is programmed through gene expression. Malforma- 
tions, thereby, represent primary errors in development, errors in chemical communication or translation of genetic information (Meteyer, 2000). The defects could be lethal, sub-lethal and nonlethal (Leipold et al., 1983). In our case, it was nonlethal.

The first morphological evidence of a limb during embryonic development is the emergence of a bulge at the appropriate level in the lateral body wall. This bulge will rapidly form a bud consisting of mesenchymal cells of mesodermal origin that are covered by the ectoderm. This apparently simple bud will develop into a complete and patterned limb under the control of a few wellidentified signaling centers. The three main signaling centers identified in the growing limb bud are the apical ectodermal ridge (AER), the zone of polarizing activity (ZPA), and the non-ridge ectoderm, each being primarily responsible for directing the growth and patterning along one of the three orthogonal axes (Talamillo et al., 2005). Alam et al, (2007) reported that any alterations in the signaling centers due to genetic, toxic or environmental factors during limb development can cause congenital anomalies of the limb.

Congenital malformation sometimes leads to mortality, and it may also

reduces the cost effectiveness and market value of defective birds. However, animals with supernumerary ectopic limbs can survive successfully with normal locomotion depending on the extent of the defect as indicated in this case study. We recommend the prompt reporting of similar cases as this will add knowledge to the distribution of defect, polymelia. It will also facilitate the search for offending compounds in the environment and the eventual establishment of their causal relationships. Poultry farmers are also advised to avoid uncontrolled or indiscriminate feeding of their birds as some of these pollutants which may be loitered in the environment may pose negative effects on the economics of poultry production.

Surgical amputation of the affected limb is a possible treatment of this deformity. However, this may not be routinely carried out in domestic birds bred for consumption, due to the negative balance of the of the surgery cost implication visa viz the monetary value of the bird.

\section{Acknowledgement}

The authors remain grateful to the staff of the Radiology Department of the University of Abuja Teaching Hospital, Abuja for their assistance in the production of radiographs. 


\section{References}

Alam, M.R., Lee, J.I., Lee, H.B., Ko J.J., Lee, K.C. and Kim, N.S. (2007). Supernumerary ectopic limbs in Korean indigenous cattle: Four case reports. Veterinarni Medicina, 52, (5): 202-206.

Albarella, S., Ciotola1, F., Dario, C., lannuzzi, L., Barbieri, V. and Peretti, V. (2009). Chromosome instability in Mediterranean Italian buffaloes affected by limb malformation (transversal hemimelia). Life Sciences \& Medicine, 24(6): 471-474.

Anderson, W. I., Langheinrich, K. A. and McCaskey, P. C. (1985). Polymelia in a broiler chicken. Avian diseases, 29: 244245.

Arunprasad, A., Dharmaceelan, S., George, R. S. and William, B. J. (2009). Polymelia in a Buffalo Calf. Tamilnadu Journal of Veterinary \& Animal Sciences, 5 (3): 116.

Bahador, S., Majid, M. and Ali, A. (2007). Notomelia and ulnar dimelia in a calf: Radiographical Anatomic Aspects. Iranian Journal of Veterinary Surgery, 2 (4): 83 - 86.

Fourie, S.L. (1990). Congenital supernumerary ectopic limbs in a Brahman-cross calf.
Journal of the South African Veterinary Association, 61: 68-70.

Harinarayana, R. S. (1992). Pygomelia in a $\mathrm{C} 3 \mathrm{H} / \mathrm{Crl}$ mouse: Case report. Labouratory Animals, 26: 228-229.

Hassan, A. Z. and Hassan, F. B. (2003). An Introduction to Veterinary Practice. Ahmadu Bello University Press Limited, Zaria, Nigeria, pp. 348.

Herec, S., Milart, Z. and Jastrzebski, M. (1986). Polymelia in lamb. Folia Morphologica (Warsz), 45:129-131.

Hays, H. and Risebrough, R. W. (1972). Pollutant concentrations in abnormal young terns from Long Island. Auk., 89: $19-35$.

Hiraga, T., Abe, M., Iwasa, K., Takehana, K. and Tetsuka M. (1989). Seven-legged calf dipygus with an extra foreleg at the pelvic region. Nippon Juigaku Zasshi, 51: 10111015.

Keeler R.F., Shupe J.L., Crowe M.W., Olson A. and Balls L.D. (1981). Nicotiana glauca-induced congenital deformities in calves: Clinical and pathologic aspects. American Journal of Veterinary Research, 42, 12311234. 
Leipold, H. W., Huston, K. and Dennis, S. M. (1983). Bovine congenital defects. Adv Vet Sci comp med. 27:197-271.

Meteyer, C.U. (2000). Field guide to malformations of frogs and toads with radiographic interpretations. Biological Science Report USGS/ BRD/BSR-2000-0005. Retrieved,from

http://www.nwhc.usgs.gov/p ublications/fact sheets/pdfs/ frog.pdf.

Newman, S.J., Bailey, T.L., Jones, J.C., DiGrassie, W.A. and Whittier, W.D. (1999). Multiple congenital anomalies in a calf. Journal of Veterinary Diagnostic Investigation, 11: 368-371.

Rahman, M. M., Khan, M. S. I., Biswas, D., Sutradhar, C. and Saifuddin, A. K. M. (2006). Pygomelia or supernumerary limbs in a cross bred calf. Journal of Veterinary Science, 7 (3): 303-305.

Rudel, R. A., Seryak, L. M. and Brody, J. G. (2008). PCBcontaining wood floor finish is a likely source of elevated PCBs in residents blood, household and dust: A case study of exposure. Environmental Health, 7: 2.

Rousseaux, C.G. and Ribble, C.S. (1988). Developmental ano- malies in farm animals. II. Defining etiology. Canadian Veterinary Journal, 29, 3040.

Sinowatz, F. (2010). Musculoskeletal system. In: Essentials of Domestic Animal Embryology (ed. Hyttel, P., Sinowatz, F. and Vejlsted, M.) Saunders, Edinburgh, pp $294-296$.

Talamillo A., Bastida M. f., Fernandez-Teran M., Ros Ma. (2005). The developing limb and the control of the number of digits. Clinical Genetics, 67, 143-153.
Corresponding Author*-

mailitopa@yahoo.com;

$+2348063234800$ 


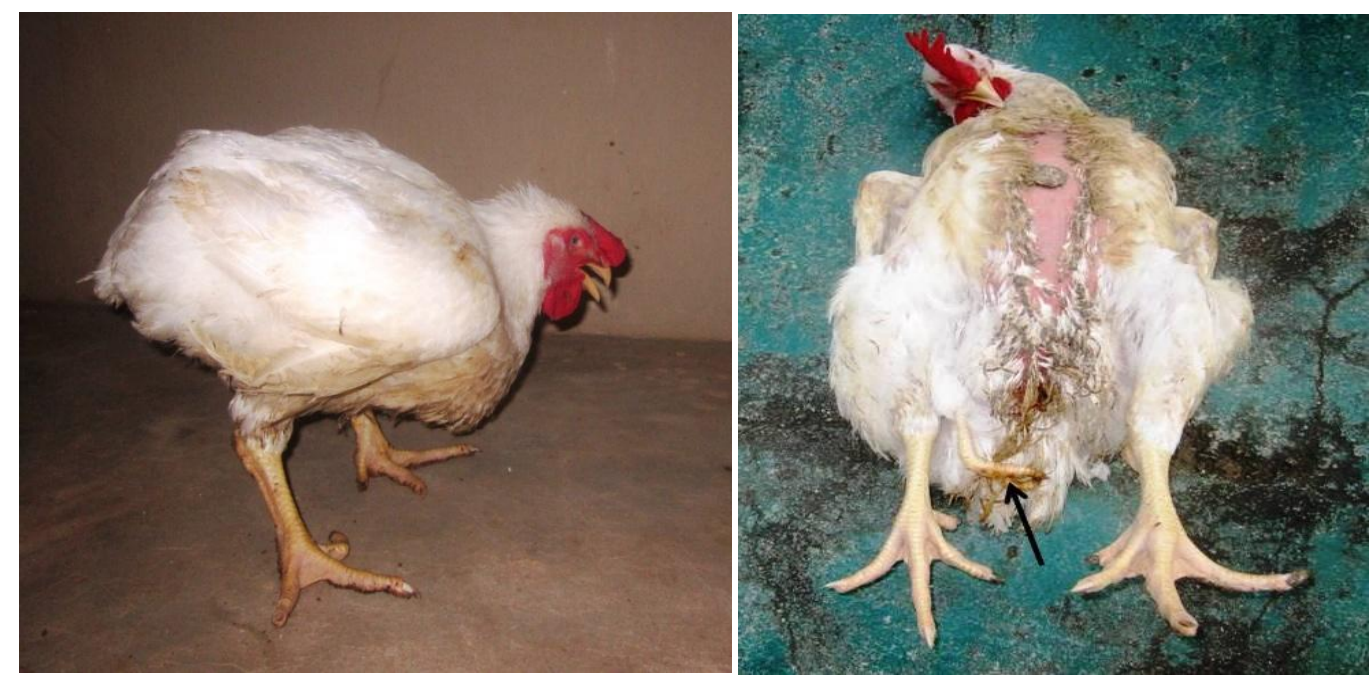

Fig (1): Picture of the affected chicken standing on the two functional limbs.

Fig (2): Ventral view of the affected chicken with arrow showing the extra limb

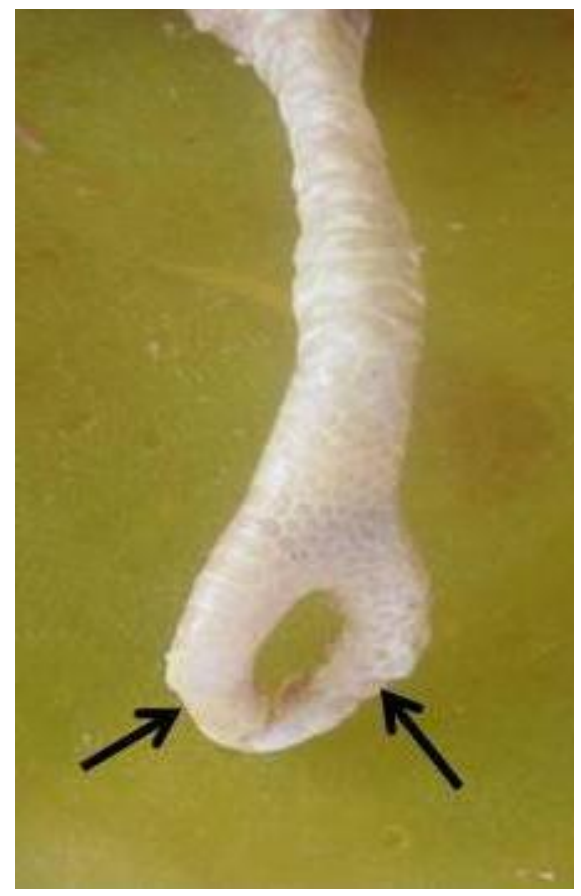

Fig (3): Picture showing the distal part of the extra limb ending with two digits. 

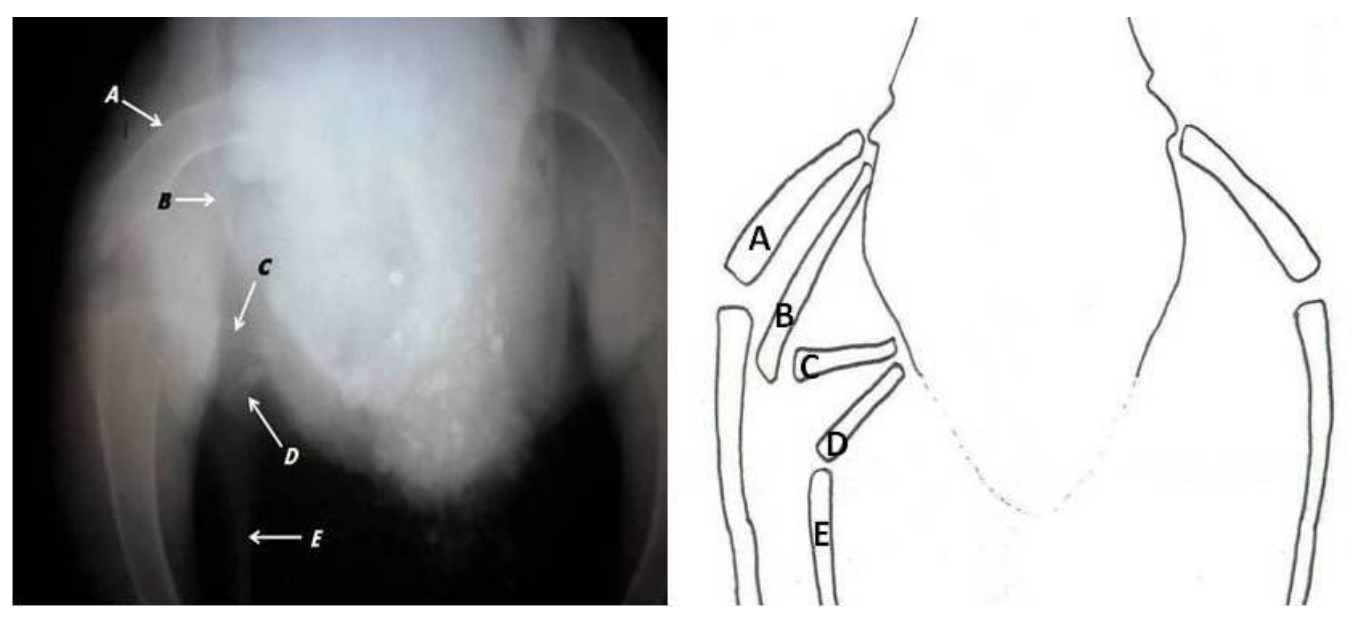

Fig (4): X-ray radiograph of the entire pelvic region of the bird showing bones of the proximal pelvic limb, A- normal right femur, B- extra femur raising from the same point of articulation as the normal femur, $\mathbf{C}$ - femur articulating with the pelvis at a point caudal to the point of articulation of ' $A$ ' and ' $B$ ', $D$ - femur raising from the same point of articulation as (C), E- extra tibia. 